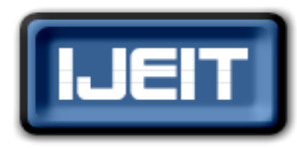

ISSN: 2277-3754

ISO 9001:2008 Certified

International Journal of Engineering and Innovative Technology (IJEIT)

Volume 10, Issue 1, July 2020

\title{
Role of 3D Printing in Food Industry- A Review
}

B Likhit $^{1}$, Dr. B V S RAO ${ }^{2}$

${ }^{1}$ UG student, ${ }^{2}$ Assistant Professor

Department of Mechanical Engineering, Chaitanya Bharathi Institute of Technology, Hyderabad.

Abstract: $3 D$ printing is the current trend in all sectors. It is very important to know about how these $3 D$ printers work, especially for those who are thinking of start-ups. $3 D$ printing revolution has already started and is having a great impact on the market.3D printing has influenced almost every sector, including the food industry. In this technical paper, how $3 D$ printing has influenced the food industry has been discussed. Several applications like, use of $3 D$ printing technology in making Pizzas, Pancakes, Artificial steak and Pasta etc. have been discussed.

Keywords: 3D printed pizza, dough, artificial steak, mold, extruder, print bed.

\section{INTRODUCTION}

We believe that for every $15-20$ years there will be revolutionary changes in our lifestyles, by this 2030 we will be experiencing these changes. It's very strange about how we change our lifestyles daily and yet remain unnoticed. The same change (a revolutionary change) is actually going to happen in the food industry in the coming years. And, in this revolutionary change, 3D Printing is going to be the game changer. We have seen how rice cookers, ovens, blenders $\&$ induction stove had an impact on the market. In the days to come everything will be automized and so is the food making process. It is going to be even simpler than it is now at the moment. The best part of having a 3D printer is that, the work gets simplified and it is possible to get unique shapes, colors $\&$ textures.

\section{3D PRINTING AND ITS WORKING MECHANISM}

Construction of a 3D model from a digital 3D model design is known as 3D printing.Initially, a $3 \mathrm{~d}$ model of a product is created using CAD program. The data is stored in an STL file format, which is commonly used file format for $3 \mathrm{D}$ printing. When used in conjunction with a 3D slicer, it allows a computer to communicate with 3D printer hardware and print the product [1].

A 3D printer extrudes molten plastic through a tiny nozzle which moves precisely under the control of a computer. It prints one layer, waits for it to dry, and then prints the next layer on top. The major parts of a 3D printer consist of an extruder, control board, filament and print bed. Fig1 shows a 3D printer [6] and Fig.2 shows 3D printer with parts labeled [7].

\footnotetext{
Manuscript received: 25 June 2020

Manuscript received in revised form: 23 July 2020

Manuscript accepted: 08 August 2020

Manuscript Available online: 15 August 2020
}

The control board is like the motherboard or main board of a 3D printer. It is the one responsible for the core operation, directing the motion components based on commands sent from a computer and interpreting input from the sensors. Filament is the material used to print objects on a $3 \mathrm{D}$ printer. It is equivalent of the ink used on a regular office $2 \mathrm{D}$ printer. It comes in a spool, which is loaded into the spool holder of the 3D printer, with the end of the filament inserted into the extruder. An extruder is the one which extrudes the material which is inside the filament, based on the command given by the control board on to a print bed. Print bed helps the object being printed to stick to the platform and allows for easier removal of completed objects.

The major advantage of having a 3D printing machine is the ability to produce very complex shapes or geometries that would otherwise be impossible to construct by hand, including hollow parts or parts with internal truss structures to reduce weight. For example, these complex shaped products shown in Fig.3 and Fig.4 are made by 3D printing [8], [9].

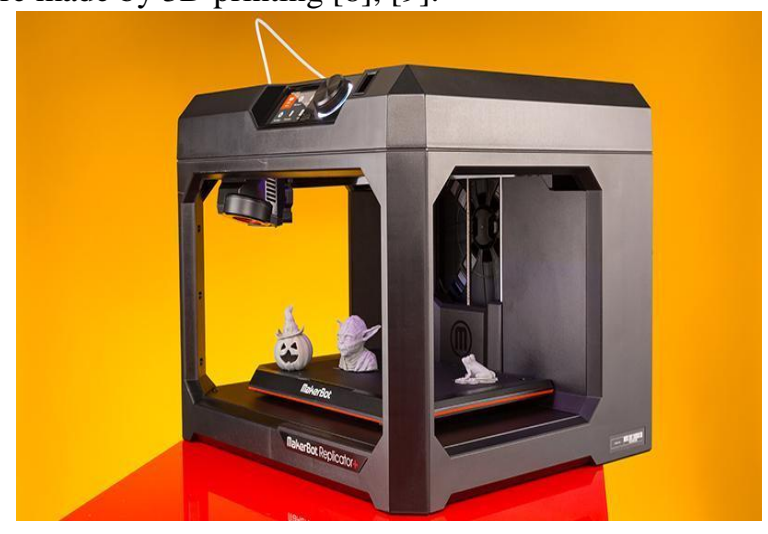

Fig 1: 3D printer

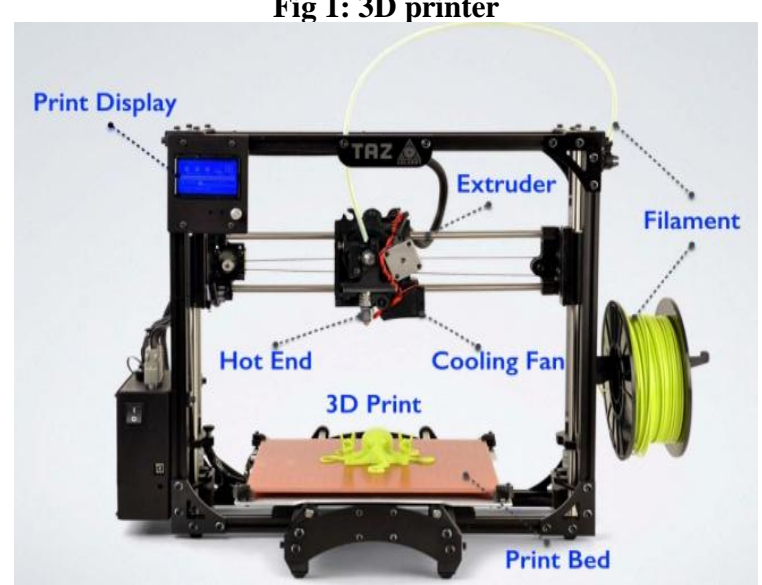

Fig 2: Parts of 3D printer 


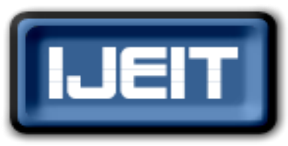

ISSN: 2277-3754

\section{ISO 9001:2008 Certified}

International Journal of Engineering and Innovative Technology (IJEIT)

Volume 10, Issue 1, July 2020
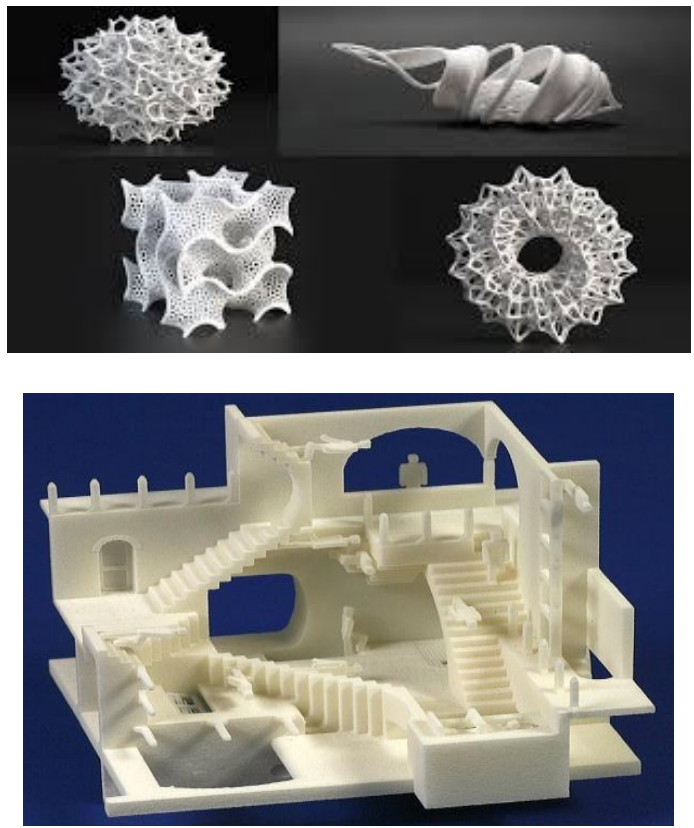

Fig 3: A complex shaped product

Producing these complex shaped products by other methods will be very tedious and time taking.It would just take a maximum of 3-4 hours to make products like this. However, the time may vary with the size and shape of the product, but it greatly gets reduced using a 3D printer.They are used to make customized products at minimum cost.

\section{APPLICATION OF 3D PRINTERS}

\section{A. Food industry}

The application of 3D printers in food industry has already started and it is believed that this machine can really do absolute wonders in the days to come. In food industry the molten plastic in the nozzle is replaced by dough [2]. Few examples of applications of 3D printers being used in the food industry include chocolates, pizzas, pasta, pan cakes etc.

\section{Bakery and allied items}

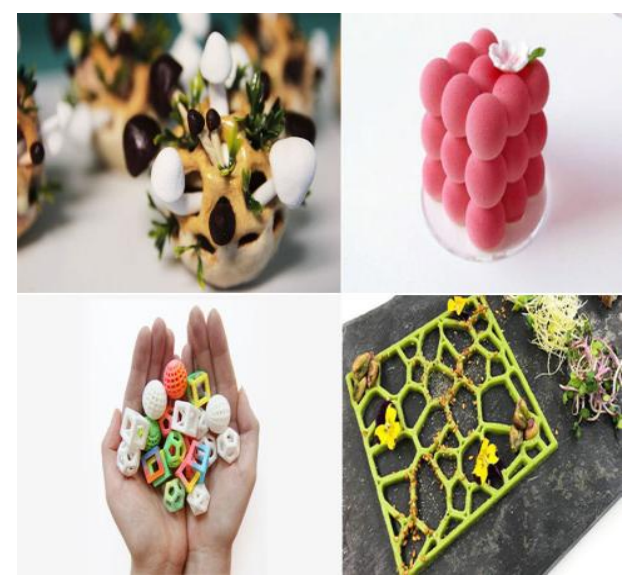

Fig.4: Edible Moulds\& Products which are made by 3D printing.
Some of the basic edible molds and products are shown in Fig. 4 which is made by 3D printer [10]. The dough can consist of different ingredients including chocolate, sugar, chewing gum and even tomato sauce.

Fig. 5 and Fig. 6 show 3D printed pizzas of different shapes [11], [12]. The pizza base can be designed to any required shape using the machine. Pizza sauce \& melted cheese will be falling on the pizza through a nozzle. With the help of a computer we can control the movements of those nozzles pipes\& make any kind of design on top.

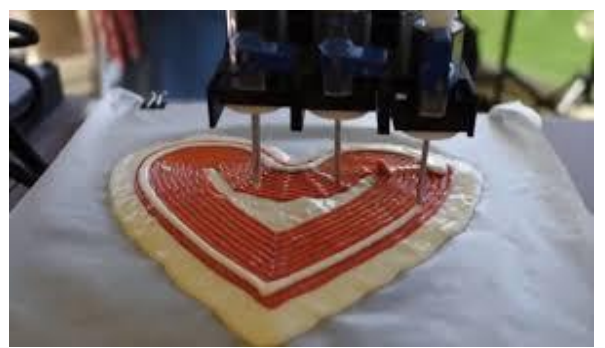

Fig 5: Heart shaped 3D printed pizza

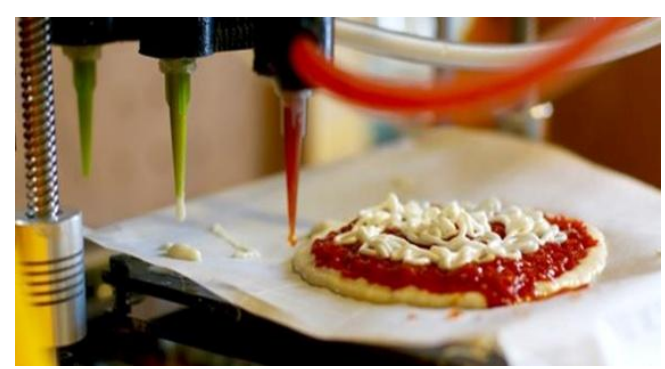

Fig.6 Circular shaped 3D printed pizza

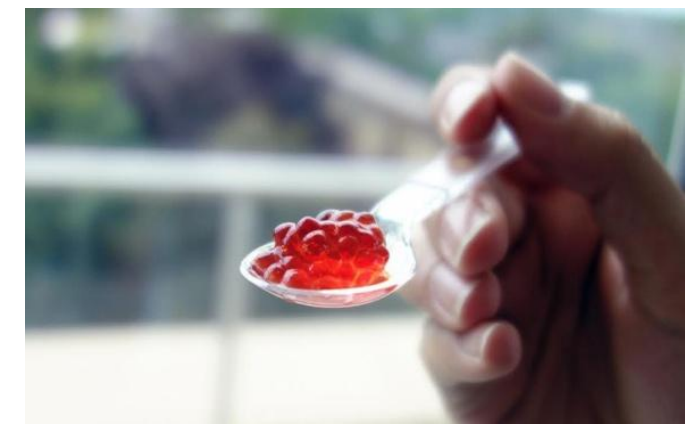

Fig.7:3D printed fruit.

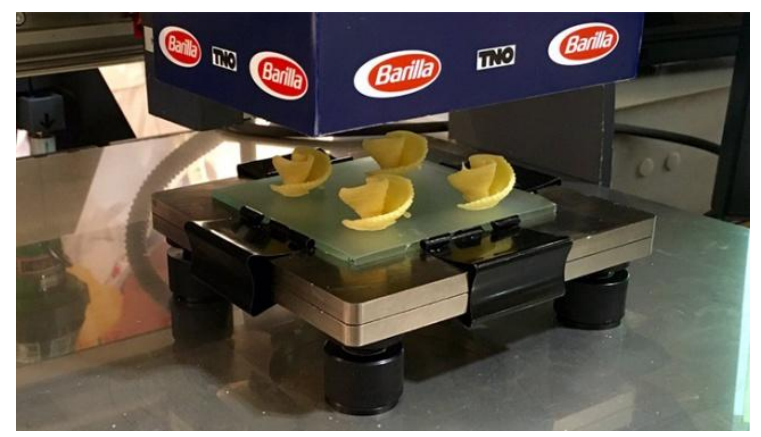

Fig.8: 3D printed pasta 


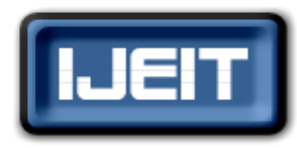

\section{ISSN: 2277-3754 \\ ISO 9001:2008 Certified \\ International Journal of Engineering and Innovative Technology (IJEIT)}

Volume 10, Issue 1, July 2020

Fig.7 shows a 3D printed fruit [13]. Dovetailed Design Studio has developed a 3D printer to create artificial fruit. The researchers change the flavors of the fruit through a combination of fruit juice and sodium alginate powder. By using different flavored juices the 3D printed fruit can be customized.

Fresh 3D printed pasta is shown in Fig.9 [14] . The machine uses a mixture of water and flour to create, layer-by-layer, pasta with unique shapes while maintaining the flavor. This was made by an Italian company Barilla. Pastas of customized shapes can be made by this machine. It gives the customers a unique experience when they can choose the shape of pasta.

3D printed cookies with unique shapes are shown in Fig.10 [15]. The dough required for cookies is filled in the extruder and the extruder is programmed to move as per the desired shape. Once the required shape is laid on butter paper it goes for baking. In the normal practice cookies are made using mould with pre-determined shapes. In this process lot of dough gets wasted. By using a $3 \mathrm{D}$ printer the requirement of mould is avoided and also the wastage of the dough is minimized.
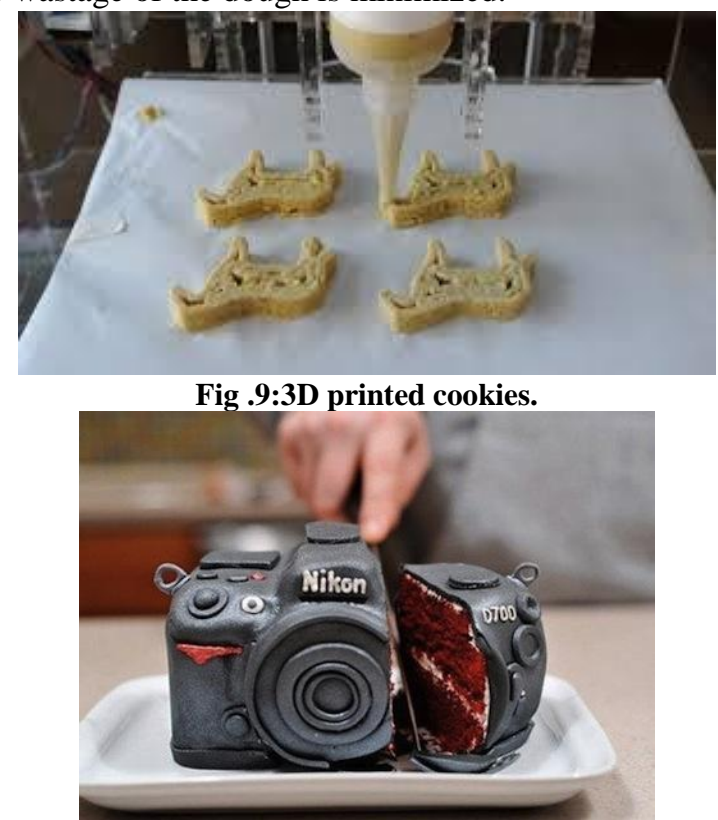

Fig.10: Customized cake.

A customized cake is shown Fig.10. [16].This is a customized birthday cake made through 3D printing.Dinara Kasko is a Ukrainian pastry chef who has already made her mark in bakery and confectionary for using 3D printing for the cakes she bakes.

Fig.11 shows a 3D printed pancake [17]. Everybody loves having pancakes for breakfast. All the pancakes almost taste the same, but this 3D printer makes these pancakes really special by giving them a unique shape. The mechanism involved in this is very simple, the pancake dough or batter is filled in the extruder\& the extruder runs by the program given in computer. Like pancakes we can also make Dosa using this 3D printer.

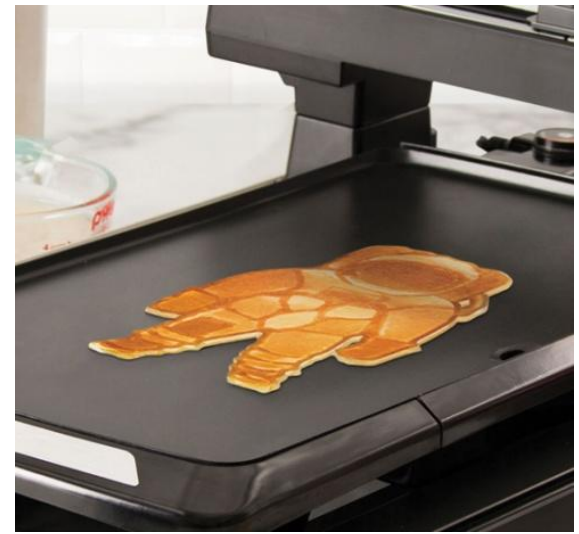

Fig.11:3D printed pancake.

\section{B. Plates and Crockery Items}

3D printed plate is shown in Fig.13 [18]. The plate is designed in such a way that when we add soya sauce the plate reveals its beauty. The left picture is before adding the soya sauce \& right picture is after adding soya sauce. 3D printed plates and glasses bring a different kind of experience to the customers. Unlike normal plates these plates are costly $\&$ are not manufactured on a large scale as $3 \mathrm{D}$ printer takes its time to design customized plates.

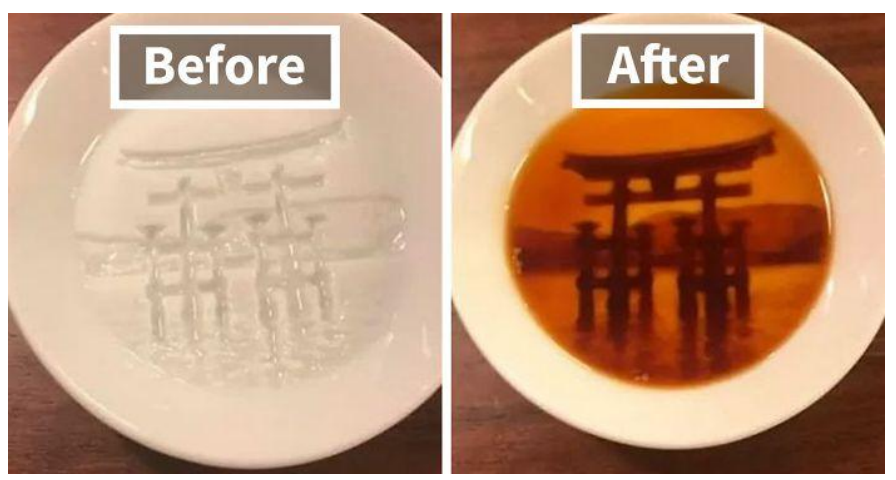

Fig.12: A 3D printed plate.

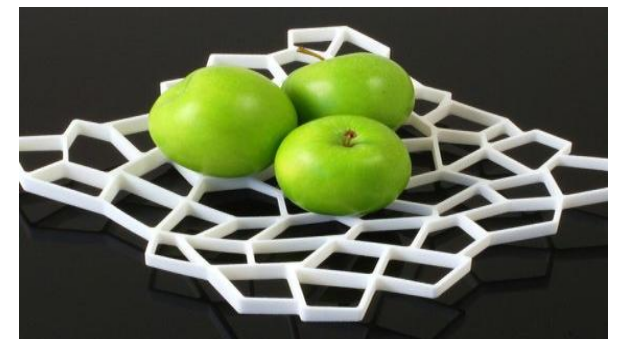

Fig.13: A 3D printed Fruit plate

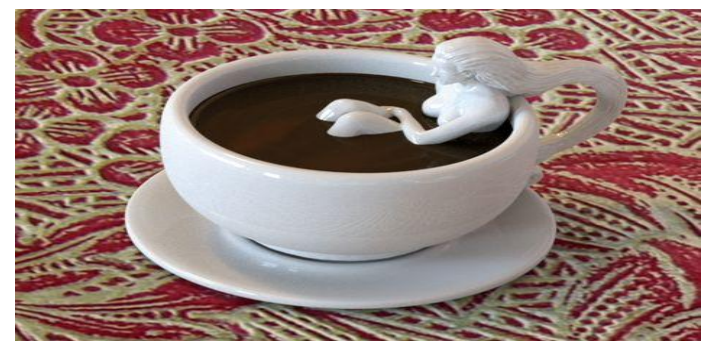

Fig.14: A 3D printed tea cup. 
ISSN: 2277-3754

ISO 9001:2008 Certified

International Journal of Engineering and Innovative Technology (IJEIT)

Volume 10, Issue 1, July 2020

Everybody likes to have some great crockery in their house. The Fig.14 shows a 3D printed fruit plate [19] and Fig. 15 shows a 3D printed cup [20]. This type of 3D printed crockery with unique shapes always gives an elegant look to every house. In the days to come almost all the crockery items will be manufactured by using 3D printing.

\section{3D PRINTED MEAT}

Fig.15 shows an artificial meat 3D printer. An Israeli firm named Redefine meat is working on this $3 \mathrm{~d}$ printed meat [21]. They believe that they would launch this by 2023. In this process they take the protein from the plants and built up in layers by a $3 \mathrm{~d}$ printer. Their main aim is to bring the same amount of protein and taste from this.Fig. 16 shows a steak that is made by a $3 \mathrm{D}$ printer. Climate change is a major concern these days [22]. The UN has stated that "The meat production is a major contributor to climate change." If this becomes successful it will be a significant turning point towards protecting the environment.

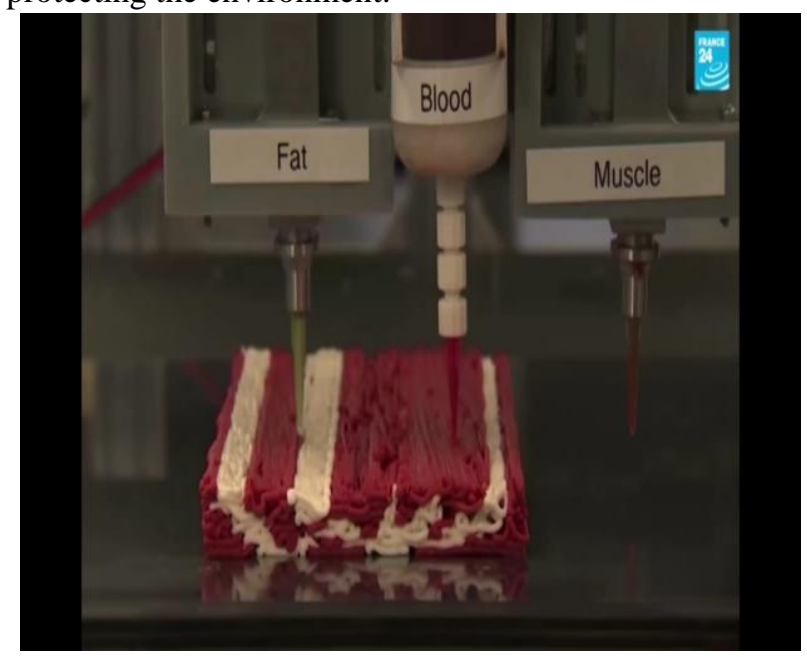

Fig.15: Artificial 3d printed meat.

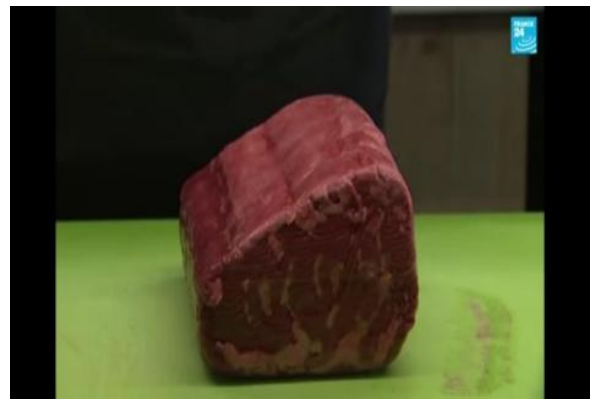

Fig.16: 3D printed steak.

Apart from all the customization \& meat production, this machine can also take care of our nutritional quotient in our daily life. This machine is being designed in such a way that, you add all the ingredients sufficient for one week \& everyday it will give you a piewhich consists of all the nutritional quotient we need. Every day the nutritional quotient can be changed according to our settings to the machine.

Having a 3D printer which makes scrambled eggs and toast for breakfast, gives a different kind of satisfaction. In the days to come we can have any ice cream of our choice by sitting at home from 3D printer. This is how the future is going to be. From food making process to delivering food, everything becomes much simpler. We humans are always fascinated about variety and automation in everything. That is what this $3 \mathrm{~d}$ printer does. It opens various ways for everything.

$3 \mathrm{D}$ food printing is on the brink of having a tremendous impact on the global economy, narrowing the gap between small and large-scale businesses, while giving customers a large degree of freedom in choosing the food they want to eat. Some of the ways in which 3D printing will affect the future of the food industry include, management of inventory for food manufacturers, bringing down costs allowing for cheaper and more sustainable food and reducing wastage of food products. Although in its nascent phase, 3D printing is poised to change the future of the food industry, and its impact is already being felt on a global scale.

\section{CONCLUSION}

- $\quad 3 \mathrm{D}$ printing is not just the current trend being used in food industry, but it is going to play a major role in every household in the days to come.

- $\quad$ Every house in the coming days is going to have at least one $3 \mathrm{~d}$ food printer like oven these days.

- 3D printed cookies, chocolates $\&$ dairy products are going to become very common in the days to come.

- 3D printing facilitates economy at low volume production.

- Using 3D printer we can have blend of Nutrition, flavor \& texture facilitating to mass customization.

- 3D printing will boost food innovation and creativity in culinary to create beautiful looking food in a variety of shapes and colors.

\section{REFERENCES}

[1] N.Shahrubudina T.C.Leea R.Ramlan , An Overview on 3D Printing Technology: Technological, Materials, and Application, Procedia Manufacturing, Science Direct, Volume 35, 2019, Pages 1286-1296.

[2] Arun Palaniappan, S. Vinodh, Rajesh Ranganathan, Analysis of factors influencing AM application in food sector using ISM, Journal of Modelling in Management, 4 January 2020, ISSN: 1746-5664.

[3] Fernanda, C.GodoiBhesh, R.Bhandari, Sangeeta Prakash, MinZhang, Fundamentals Of 3D Food Printing And Applications. ISBN-978-0-12-814564-7, 2019, Science Direct, Academic Press. 
ISSN: 2277-3754

ISO 9001:2008 Certified

International Journal of Engineering and Innovative Technology (IJEIT)

Volume 10, Issue 1, July 2020

[4] Zhenbin Liu, Min Zhang, Bhesh Bhandari, YuchuanWang, 3D printing: Printing precision and application in food sector, Trends in Food Science \& Technology, August 2017.

[5] Paphakorn Pitayachaval, Nattawut Sanklong and Anantapoom Thongrak, A Review of 3D Food Printing Technology, MATEC Web of Conferences 213, 01012 (2018) ACMME 2018.

[6] https://in.pcmag.com/printers/37989/the-best-3d-printersfor-2020.

[7] http://my3dconcepts.com/explore/main-components-ofdesktop-3d-printers/.

[8] https://3dprintingforbeginners.com/an-introduction-to-3dprinting-services/

[9] https://www.pinterest.com/pin/198088083586342004/.

[10] https://www.3dnatives.com/en/food-3dprinting220520184/.

[11] https://all3dp.com/2/3d-printed-pizza-myth-or-reality/.

[12] https://futurism.com/nasa-astronauts-can-now-3d-printpizzas-in-space.

[13] https://3dprint.com/4314/3d-printed-fruit-microsoft/.

[14] https://interestingengineering.com/9-examples-of-how-3dprinting-will-change-the-way-you-eat.

[15] https://panorender.com/3d-food-printing-3d-printingcookies-santa/.

[16] https://3dprint.com/12793/3d-cake-creator-printer/.

[17] https://www.hammacher.com/product/3d-pancake-printer.

[18] https://www.boredpanda.com/dishes-sauce-images-appear3d-print-japanese-

redestu/?utm_source=google\&utm_medium=organic\&utm _campaign=organic.

[19] https://www.pinterest.com/pin/230246599673732230/.

[20] https://in.pinterest.com/pin/387942955377181152/.

[21] https://www.youtube.com/watch?v=fLpeeUYtW94.

[22] https://www.youtube.com/watch?v=fLpeeUYtW94. 